\title{
Why are there fewer frogs and lizards in Southeast Asia than in Central America?
}

\section{from Robert M. May}

IT has long been suspected that the densities of floor-dwelling amphibians and reptiles are lower in the rainforests of Southeast Asia than in those of Central America.

The first quantitative analysis, however, was made by Scott (Biotropica 8, 41; 1976), who compared his data from two Costa Rican forests with that of Lloyd et al. ( $\mathrm{Am}$. Nat. 102, 497; 1968) from Nanga Tekalit in Borneo. Inger ( $A$ m. Nat. 115, 761; 1980) has recently widened the scope of such comparisons, combining his own additional data from Bornean, Malayan and Thailand forests with Heatwole and Sexton's (Am. Midl. Nat. 75, 45; 1966) results for Panamanian rainforests. The main results are summarized in the Table.

By and large, the numbers in the Table are for floor-dwelling creatures, omitting arboreal and riparian-terrestrial animals (though the Panamanian study includes some lizards captured on trees). Inger notes that turtles and snakes were found too rarely for it to matter whether they are included; similarly, the Costa Rican numbers are little affected by adding in salamanders (as Scott did).

Inger presents further data on the daily catch of frogs and lizards in two other rainforest sites in Borneo, and in three sites (rainforest, logged forest, rubber planting) in Malaya. Although absolute estimates of individuals per $\mathrm{m}^{2}$ are not available for these sites, the number of catches per day in the rainforest sites were so similar to those in the Old World sites listed in the Table that it is reasonable to assume the densities would also have been similar. On the other hand, the catch per day in the two disturbed sites (logged forest and rubber plantings in Malaya) were more than twice the rates in undisturbed Old World rainforests. Inger suggests this may be due to environmental factors, or to the abundance of species that might be called commensals of man; it could alternatively be due to the enhanced abundance often associated with the ' $r$-selected' species that characterize disturbed habitats.

The Table shows a consistent pattern, with the total density of frogs and lizards in rainforests in the New World being an order of magnitude higher than those in Southeast Asia. This overall pattern conceals some interesting details. One such is the reversal of the preponderance of frogs over lizards as one goes from Borneo to Thailand; Inger and Colwell (Ecol. Monogr. 47, 229; 1977) attribute this to the relatively dry, harsh seasonal climate of the Thailand sites, which would favour reptiles over amphibians.

What is the explanation for the striking

Robert M. May is Class of 1877 Professor of Zoology at Princeton University. differences revealed in the Table? In terms of ecological roles, species of frogs and lizards dwelling on the floors of tropical forests are very similar; in both Old and New Worlds, the majority feed on arthropods and other invertebrates, and both groups inhabit the same kind of microhabitat. The total number of species of frogs and lizards (species richness) is not

Comparison of densities of floor-dwelling amphibians and reptiles in lowland $(<500 \mathrm{~m})$ forests of Old and New World tropics.

\begin{tabular}{lccc}
\hline \multirow{2}{*}{\multicolumn{1}{c}{ Place }} & \multicolumn{3}{c}{ Individuals per $100 \mathrm{~m}^{2}$} \\
\cline { 2 - 3 } & Frogs & Lizards & Combined \\
\cline { 2 - 3 } $\begin{array}{l}\text { Borneo: Nanga Tekalit } \\
\text { Thailand: Sakacrat }\end{array}$ & 1.31 & 0.25 & 1.56 \\
$\quad$ evergreen forest & 0.12 & 1.03 & 1.15 \\
$\quad$ deciduous forest & 0.27 & 1.22 & 1.49 \\
Costa Rica: Ricon de Osa & 11.6 & 3.9 & 15.5 \\
Costa Rica: La Selva & 14.7 & 2.8 & 17.5 \\
Panama: Silugandi & 29.8 & 15.4 & 45.2 \\
\hline
\end{tabular}

significantly different between the two hemispheres. The abundance of snakes or other important predators of frogs and lizards does not show systematic differences.

Scott attributes the difference in density to there being less production of litter in Bornean forests. But Inger shows some of the estimates of litter production in Bornean forests used by Scott are inappropriate (coming from impoverished heath forests), while others have been revised upward by later work. It does not now seem that production of litter varies much among the major tropical rainforests.

Inger's explanation begins with the observation that a high proportion of the trees in Indo-Malayan rainforests are members of one family, the Dipterocarpaceae. Dipterocarps are noted for their synchronized mast fruiting, which often involves more than 100 species over thousands of square kilometers; the intervals between such reproductive explosions exceed one year. This phenomenon has, however, not been reported for trees in Neotropical forests. Inger suggests that "Mast fruiting should lead to reduction in abundance of an entire class of arthropod primary consumers during non-mast years. In turn, this reduction should affect the total size of the insect population and, therefore, the numbers of insectivorous secondary consumers, such as frogs and lizards. Since ripe dipterocarp seeds do not hang but fall to the ground, it is likely that a reduction in the numbers of seed-eating insects and their arthropod predators would have its greatest effect on the food supply of terrestrial rather than arboreal frogs and lizards."

Inger notes that his hypothesis is susceptible to several tests. If his ideas are correct, both the total number of insects, and the proportion comprising fruit and nut eating insects, should be lower on the floors of Southeast Asian forests than in the Neotropics. Similarly, we would expect to find fewer insectivorous birds feeding on or near the ground.

If Inger's suggestions survive these tests, the problem will have been pushed back one notch. We will then need to understand whether it is historical accident or systematic environmental differences that have produced spectacularly synchronized mast fruiting in Southeast Asian forests and not in the New World.

\section{Neurotoxicity: Mechanisms explored and exploited}

from M.K. Johnson

NEw knowledge of the mechanism of delayed neurotoxicity of some organophosphorus esters is enabling realistic assessment of hazardous levels of exposure. Tri-aryl and mixed alkyl-aryl phosphate esters are widely used as hydraulic fluids, flame retardants and plasticisers and, in both agriculture and disease vector control programmes, organophosphorus pesticides are now used in preference to the persistent halogenated hydrocarbons. Some, but not all, of these esters cause delayed neuropathic effects when tested in sensitive species such as hens or cats and similar neuropathies have occurred in man after ingestion of organophosphates. There is an interval of 10-15 days between ingestion of a neuropathic ester and the onset of clinical signs and, until recently, clinical observation has been the most sensitive tool of the neurotoxicity tester.

At a recent conference* the primary causal molecular changes were presented and the ways in which this knowledge could

M.K. Johnson is in the MRC Toxicology Unit, Carshalton, Surrey, UK. 